\title{
Software de comunicação For-Chat
}

\section{Autores:}

\author{
Daniela Peño Paiva \\ Fábio Medeiros \\ Tiago Stürmer Daitx \\ Margarete Axt
}




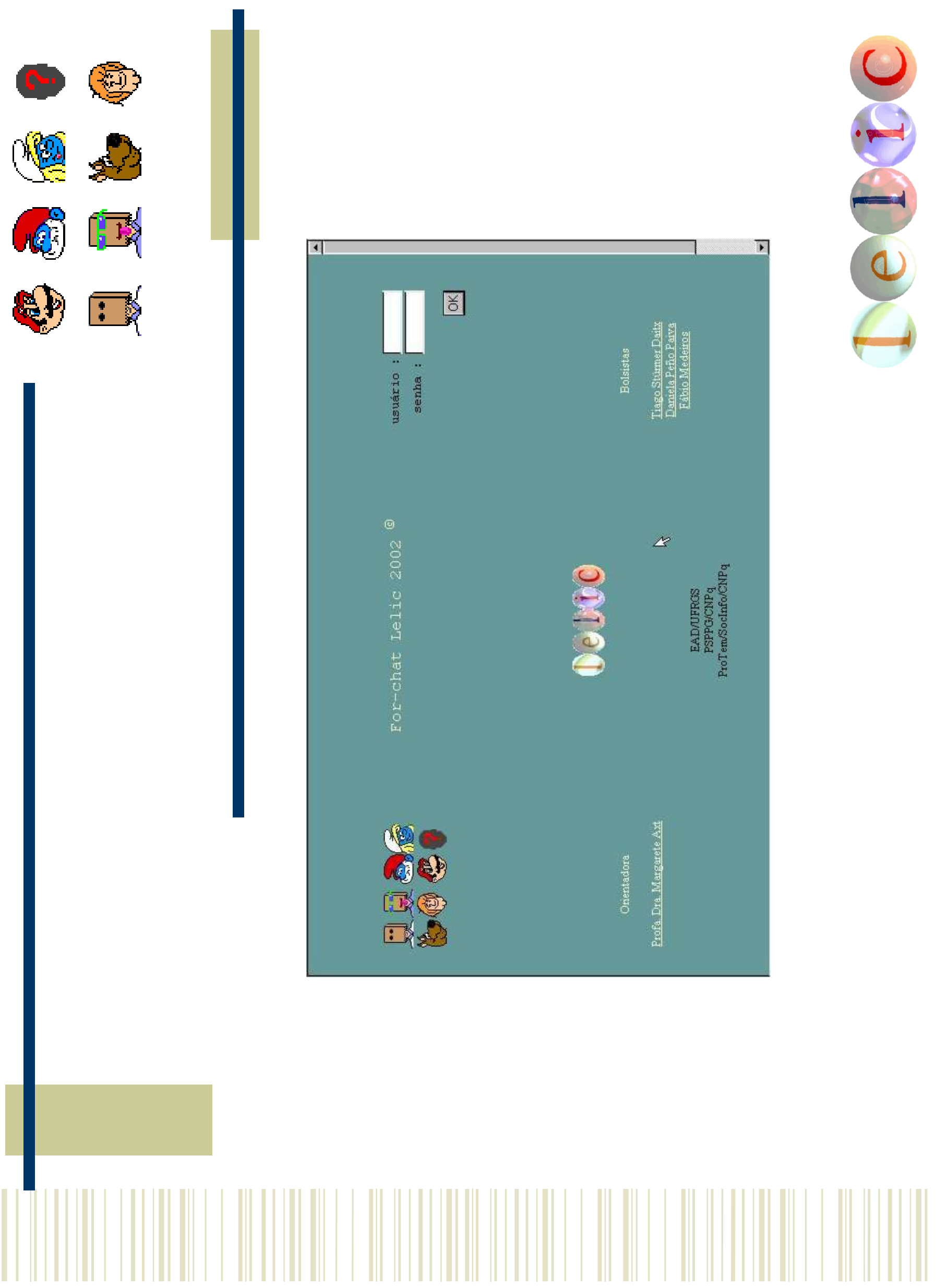




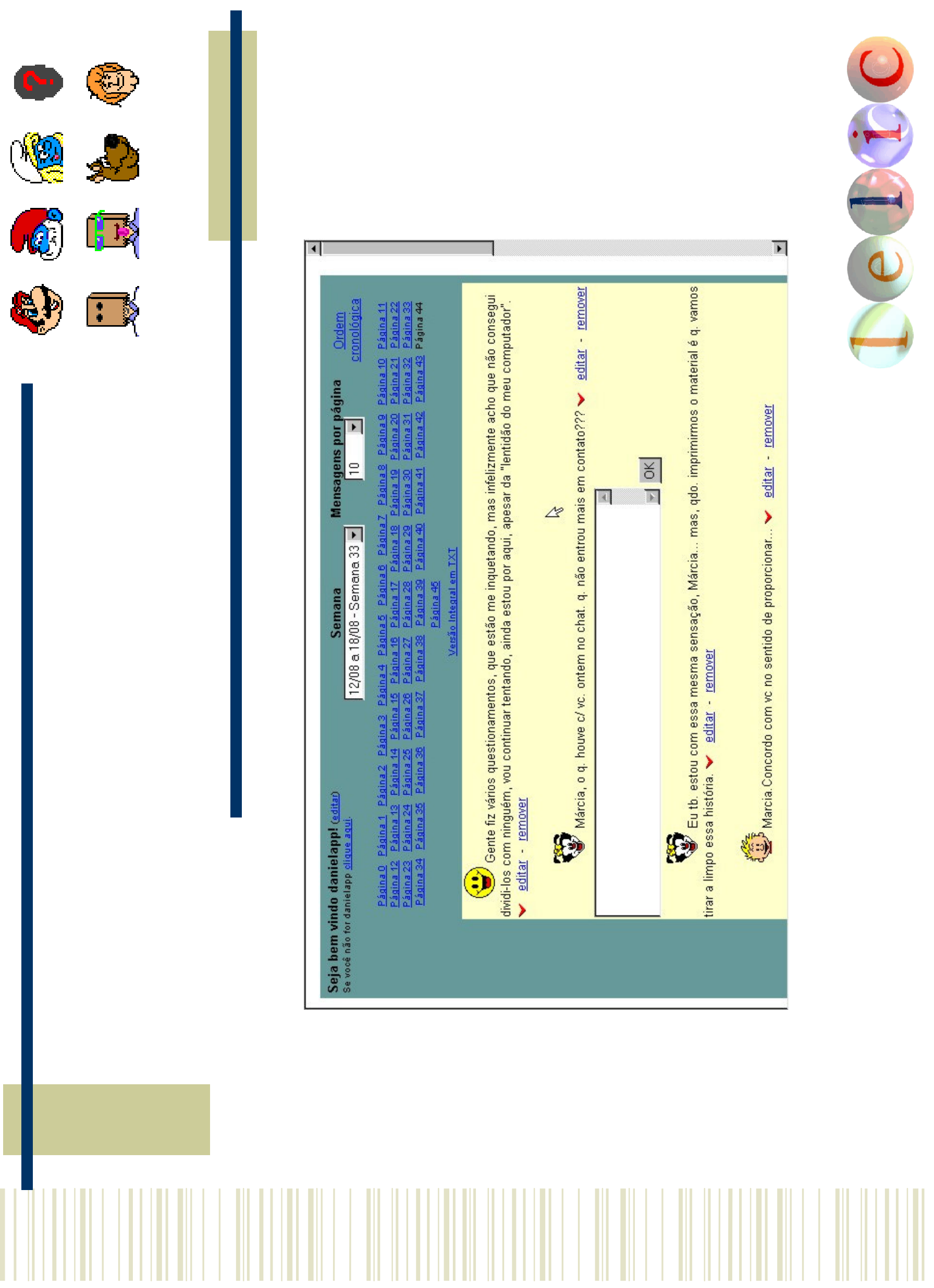




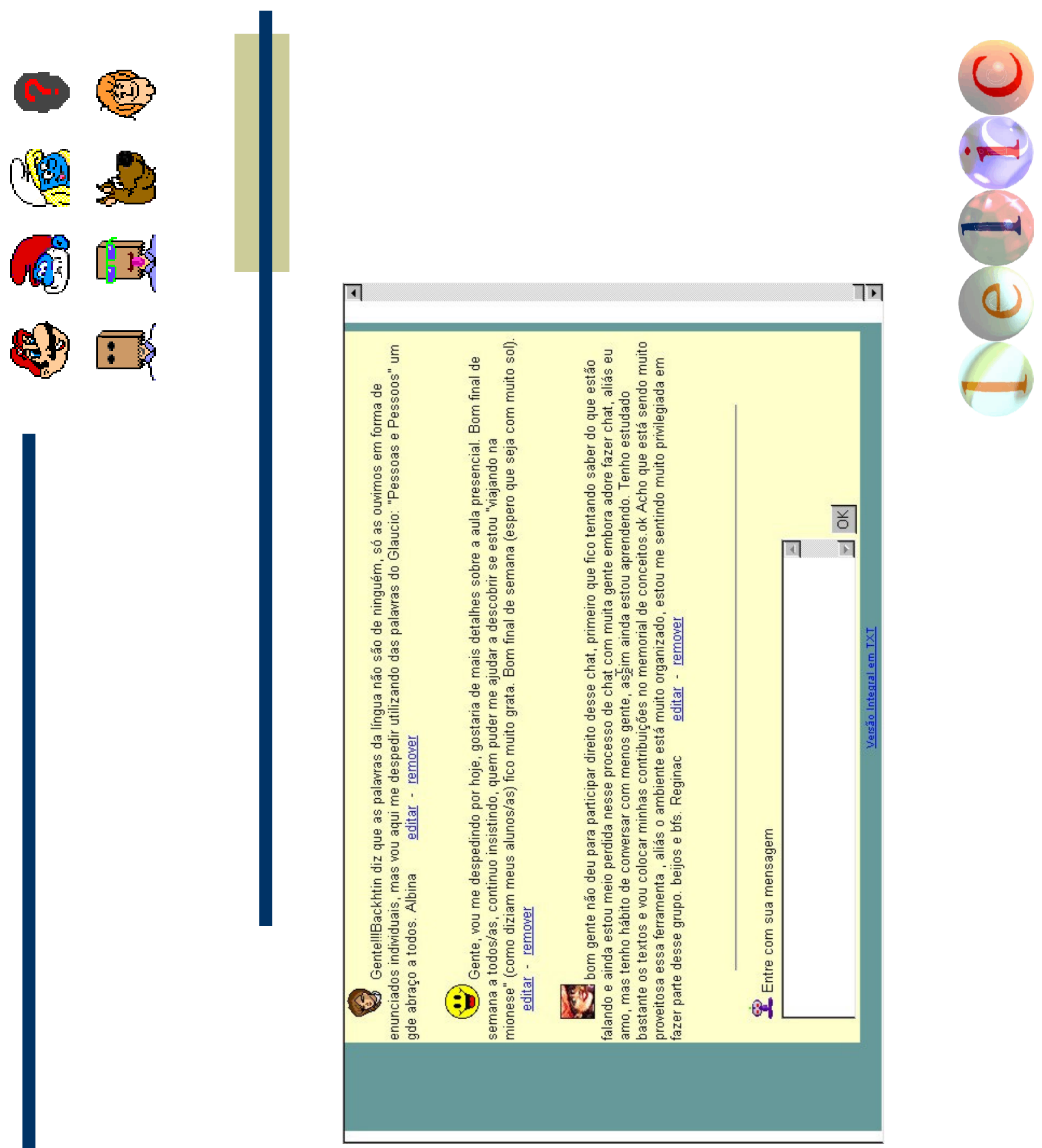




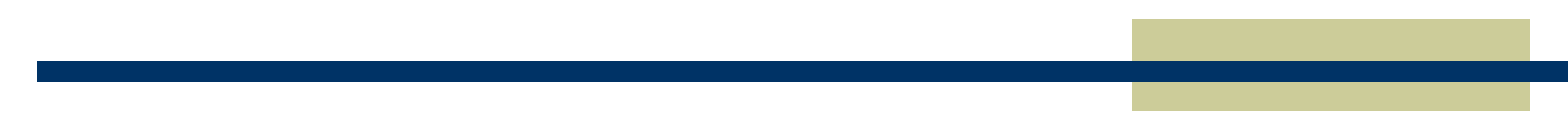

http://www.lelic.ufrgs.br/plataforma/forum/login.htm 


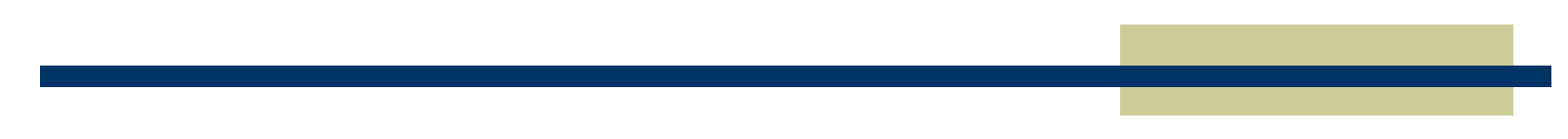

O que é o For-Chat? 


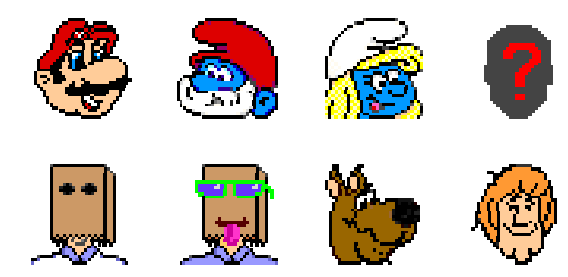

O que é o For-Chat?

O software de comunicação For-Chat é uma mescla de três ferramentas de Educação à Distância, um fórum, chat e mural eletrônico. 


\section{䌿 \\ 基量}

\section{A estrutura do For-Chat}




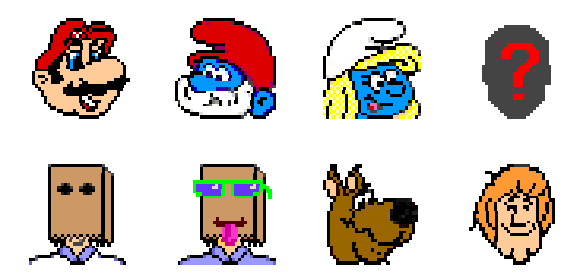

\section{A estrutura do For-Chat}

A estrutura do software baseia-se no

armazenamento de mensagens em um banco de dados MySQL, ordenadas através de uma página em PHP para posterior exibição em um browser. 


\section{通繦 \\ 基量}

\section{Origem do For-Chat}




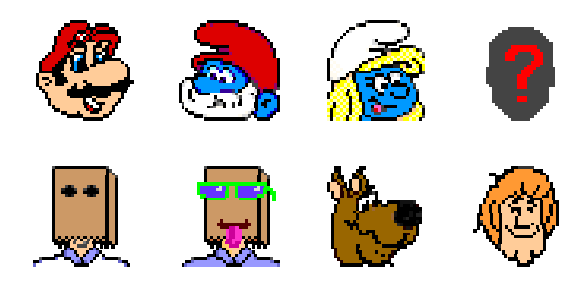

\section{Origem do For-Chat}

Uma das propostas do Projeto PRO-VIA

(Comunidades Virtuais de Aprendizagem), é o desenvolvimento de metodologias de interação que potencializem a estruturação de uma rede virtual de discussões. 


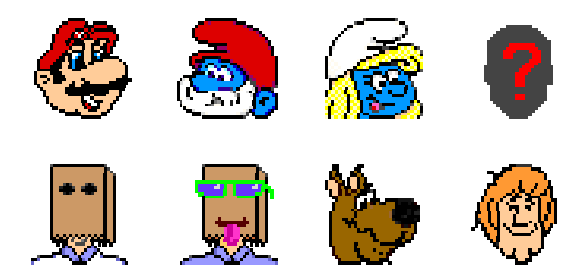

\section{Origem do For-Chat}

Foi criado para interações síncronas e assíncronas desenvolvidas em ambientes virtuais de suporte à aprendizagem. 


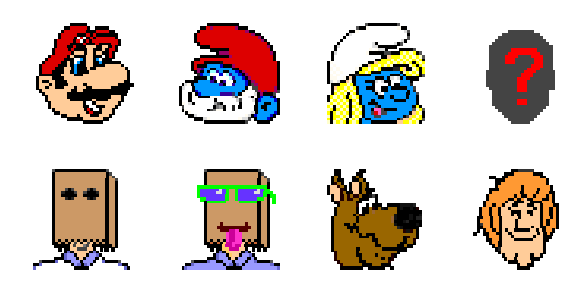

\section{Características do For-Chat}




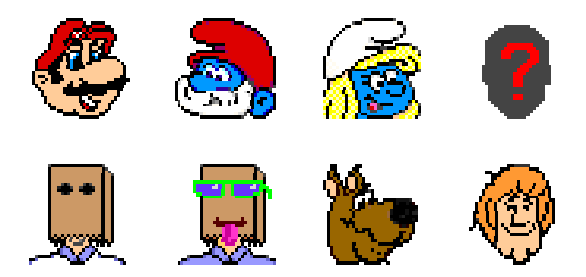

Características do For-Chat

Os usuários podem interagir de maneira não linear, adicionando tópicos em qualquer parte da discussão. 


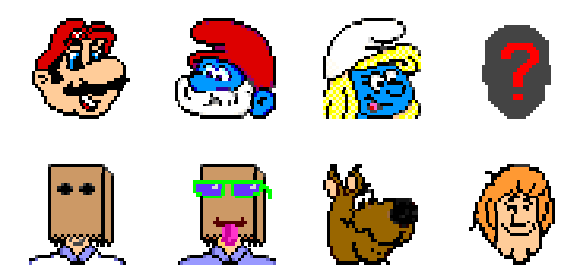

Características do For-Chat

A discussão é mantida na íntegra com o escalonamento por semanas, o que diferencia o For-Chat de um chat convencional. 


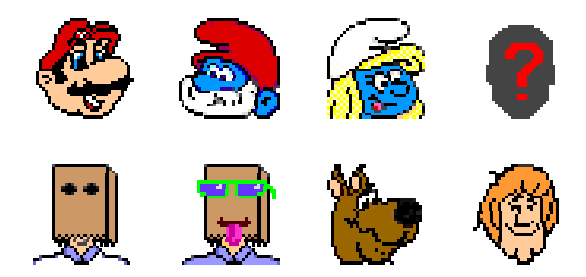

Características do For-Chat

\begin{abstract}
A discussão proposta pode ter inicialmente uma temática única, lembrando um fórum tradicional, porém, temos a possibilidade de ter diversas temáticas sendo desenvolvidas caracterizando uma maior diversidade de interações.
\end{abstract}




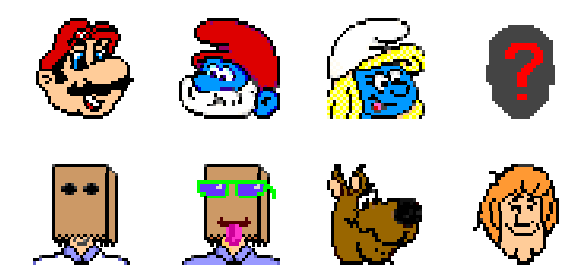

Características do For-Chat

A discussão é integralmente mantida, mesmo com o passar das semanas. O usuário "entra" no For-Chat e pode acompanhar discussões anteriores com a possibilidade de se unir ao grupo a qualquer momento. 


\section{䌿 \\ 基量}

\section{Aplicações do For-Chat}




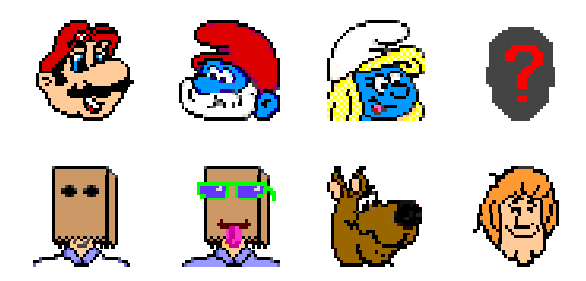

Aplicações do For-Chat

O software é utilizado atualmente em diversos níveis de ensino. Iniciou sua aplicação na disciplina Psicopedagogia Terapêutica I, do Curso de Graduação em Pedagogia da UFRGS. 


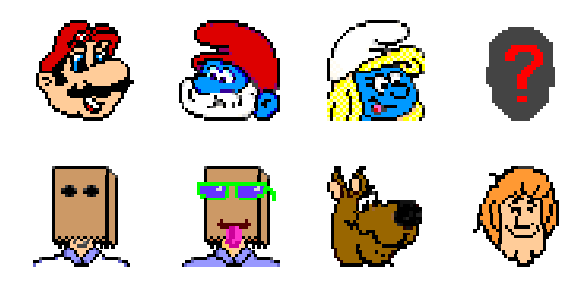

\section{Aplicações do For-Chat}

O Mestrado à Distância também utilizou o For-Chat em algumas de suas disciplinas, mais especificamente no Seminário Avançado: Sentido e Autoria em Ambientes Virtuais de Aprendizagem: Condições de Possibilidade, In(ter)venção e Avaliação. 